\title{
Spatial Distribution and Pollution Assessment of Heavy Metals in Soils in the Jiefangzha Irrigation Area of the Hetao Irrigation District, China
}

\section{Qi Zhang ( $\square$ 15849170898@163.com )}

Inner Mongolia Agricultural University https://orcid.org/0000-0002-6199-9191

\section{Qingfeng Miao}

Inner Mongolia Agriculture University: Inner Mongolia Agricultural University

Junping Lu

Inner Mongolia Agriculture University: Inner Mongolia Agricultural University https://orcid.org/00000003-0678-0290

\section{Linfeng Yuan}

Inner Mongolia Agriculture University: Inner Mongolia Agricultural University

\section{Guoxia Pei}

Inner Mongolia Agriculture University: Inner Mongolia Agricultural University

\section{Research Article}

Keywords: farmland soils, heavy metals, Jiefangzha Irrigation Area, spatial distribution, pollution assessment

Posted Date: November 23rd, 2021

DOI: https://doi.org/10.21203/rs.3.rs-1072604/v1

License: (9) This work is licensed under a Creative Commons Attribution 4.0 International License.

Read Full License 


\section{Spatial distribution and pollution assessment of heavy metals in soils in the Jiefangzha Irrigation Area of the Hetao Irrigation District, China}

Qi Zhang 1,\#, Qingfeng Miao, ${ }^{1, \#}$, Junping Lu1,* ,Linfeng Yuan1, Zhenyu Shi 1, Feng Shen

2 ,Guoxia Pei ${ }^{1}$, Yanlin Zeng ${ }^{1}$

1.Water Conservancy and Civil Engineering College, Inner Mongolia Agricultural University, Hohhot 010018,China; ylf66662021@126.com

2. OtogBanner Public Utilities Development Center, Ordos 017000 ,China

* Correspondence: lujunping2008@163.com

\# These two authors contributed equally to this work.

Abstract: To explore the characteristics of heavy metal pollution in farmland soils in the Jiefangzha Irrigation Area of the Hetao Irrigation District, Inner Mongolia, 60 samples of the surface soil $(0-20 \mathrm{~cm})$ of the irrigation area were collected to detect and analyze the content of the typical heavy metal elements $\mathrm{Cu}, \mathrm{As}$, and $\mathrm{Pb}$ in the soil. The methods utilized included the single factor index method, the Nemerow index method, the geological accumulation index method, and the potential ecological hazard index method to evaluate their pollution and ecological risks, and these were combined with geostatistical methods using GIS technology to quantitatively analyze their spatial distribution characteristics. The results showed that the average content of $\mathrm{Cu}, \mathrm{As}$, and $\mathrm{Pb}$ did not exceed the background values in the Hetao Irrigation Area, and the contents showed a moderate variation, with the order of variation as $\mathrm{As}>\mathrm{Cu}>\mathrm{Pb}$. The multivariate statistical analysis results showed that the three elements, $\mathrm{Cu}, \mathrm{As}$, and $\mathrm{Pb}$, had similar sources, being primarily the use of agrochemicals, such as fertilizers and pesticides. The semi-variance function model fitting results showed that $\mathrm{Pb}$ was a spherical model, and $\mathrm{Cu}$ and As were Gaussian models. The Kriging interpolation showed that the contents of $\mathrm{As}, \mathrm{Pb}$, and $\mathrm{Cu}$, in general, showed a trend that was higher in the northwest and lower in the southeast, with a change of gradient increasing from the southeast to the northwest. Human activities were the primary factors that were causing the distribution difference.

Keywords: farmland soils; heavy metals; Jiefangzha Irrigation Area; spatial distribution; pollution assessment

\section{Introduction}

Soil is an important part of the terrestrial ecosystem and the key to sustaining life on earth. It can supply nutrients necessary for plant growth, and is not only the destination of heavy metals but also the medium for heavy metals to spread to the atmosphere, organisms, and water[1,2]. Heavy metals in soil are complex, concealed, hysteretic, cumulative, and irreversible[3,4], and they are extremely difficult to treat. This leads to crop production reductions and agricultural product pollution[5,6]. Finally, excessive accumulation in the human body through the food chain threatens human health. Heavy metal pollution has become a serious problem in the world, which has attracted extensive attention from society and academic circles. 
The Inner Mongolia Hetao Irrigation Area is the national important production base of commodity grain and oil, and the Inner Mongolia autonomous region is one of the largest yellow irrigation areas of our country. In recent years, the Yellow River basin violations of pollutant emission standards have led to increasing degrees of water pollution[7,8], and the use of agricultural chemicals, such as fertilizers and pesticides, and the liberation of brake irrigation field water and soils are serious threats. In addition, Wuliangsuhai is the only bearing and discharging channel of the Hetao Irrigation Area, and the pollution substances carried by farmland drainage cause ecological risks to Wuliangsuhai. Currently, many scholars have studied soil salinization[9], persistent organic pollutants[10], and changes in the groundwater level in the Jiejiangzha Irrigation Area of the Hetao Irrigation Area[11], but there are a few studies that have examined heavy metals in the farmland soils of this irrigation area. Therefore, single-factor and multi-factor evaluation methods are used in this study to evaluate the pollution degree and potential ecological harm of the heavy metals $\mathrm{Cu}, \mathrm{As}$, and $\mathrm{Pb}$ in the farmland soils of the Jiefangcha Irrigation Area and to analyze the source and spatial distribution of heavy metals in this study area. This is accomplished by combining a multivariate statistical analysis, GIS, and geostatistical methods. This study provides a scientific basis for farmland protection and the comprehensive control of heavy metal pollution in this area.

\section{Materials and methods}

\subsection{Study area}

The Jiefangzha Irrigation Area has a very long history beginning from the Qin and Han Dynasties and prospering in the late Qing Dynasty. According to historical records, it has a development history of more than 2,000 years. It is one of the earliest large-scale irrigation areas of the Yellow River irrigation development in the Hetao Irrigation Area of Inner Mongolia. The Jiefangzha Irrigation Area is located in the central and western side of the Hetao Irrigation Area of Inner Mongolia. Its geographical coordinates are $106^{\circ} 43^{\prime}-107^{\circ} 27^{\prime} \mathrm{E}$ and $40^{\circ} 34^{\prime}-41^{\circ} 14^{\prime} \mathrm{N}$. It belongs to the cold and arid area of northwest China. It is a typical irrigated agricultural area. The annual average water volume of the Yellow River diversion irrigation in the irrigated area is approximately 1.2 billion $\mathrm{m}^{3}$, and the annual displacement is approximately 200 million $\mathrm{m}^{3}$. The main crops are corn, wheat, oil, and others.

\subsection{Sample collection and determination}

According to the Technical Specification for Monitoring Farmland Soil Environmental Quality and the geographical characteristics and irrigation characteristics of the Jiefangzha Irrigation Area, the S-type distribution method was adopted. In June 2019, soil surface samples $(0-20 \mathrm{~cm})$ were collected, and a total of 60 sampling points were established, as shown in Figure 1. During the sampling process, approximately $1 \mathrm{~kg}$ of soil samples was collected from each sampling point and placed into a polyethylene plastic bag to prevent cross-contamination.

The collected samples were naturally air-dried in the laboratory, and after removing impurities from the samples, the samples were crushed with a wooden tool, ground through a 100-mesh sieve using an agate mortar, and put into a polyethylene plastic bag for use. The soil samples were digested using a microwave with $\mathrm{HNO}_{3}-\mathrm{HCL}-\mathrm{HF}$. The contents of the $\mathrm{Cu}$, As, 
and $\mathrm{Pb}$ were analyzed using inductively coupled plasma mass spectrometry (ICP-MS). All of the reagents in the analysis were of excellent purity, and all the samples were tested in parallel.

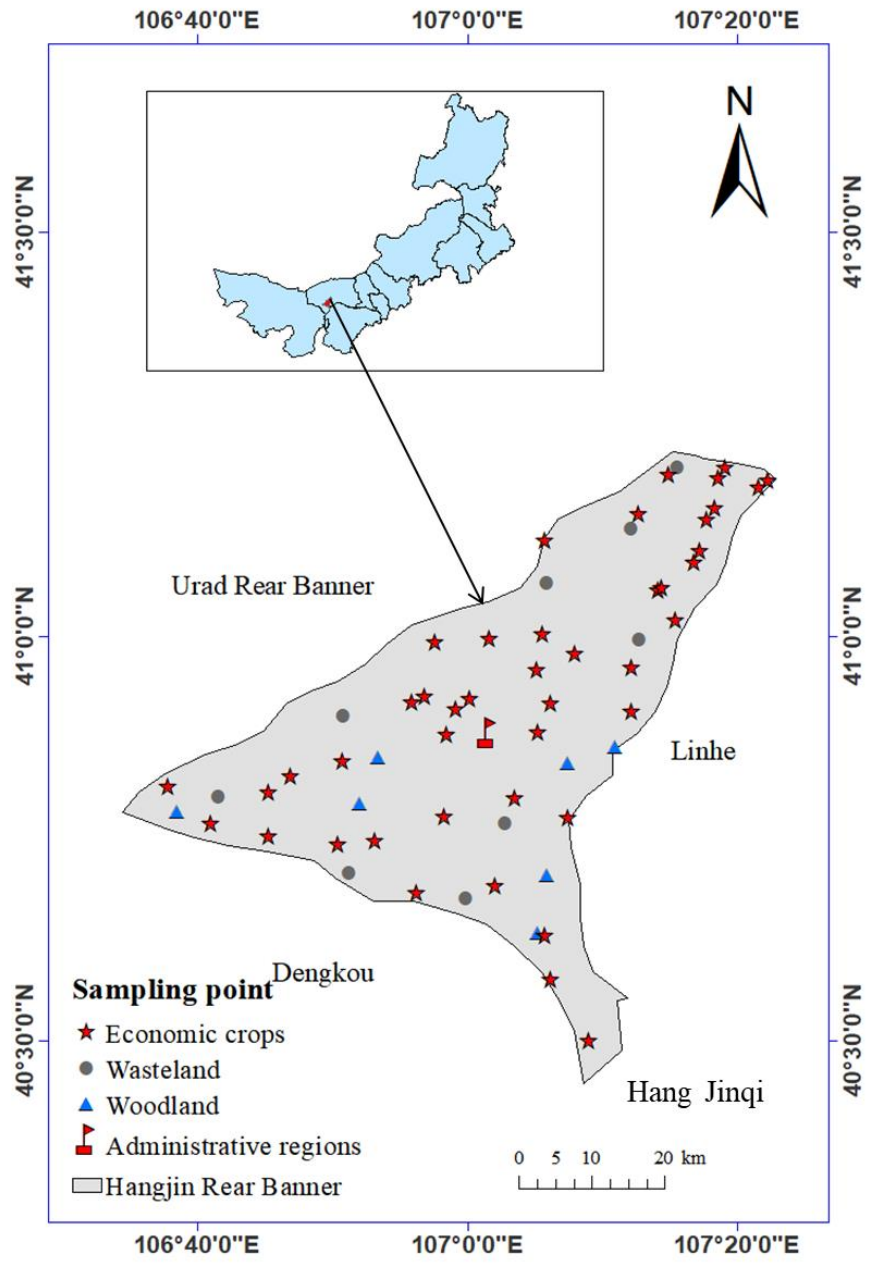

Figure 1 Distribution of study area and sampling points

\subsection{Data statistics and analysis}

During the process of data analysis, SPSS26 software was used for the statistical analysis, the principal component analysis, and the normal distribution test. GS+9.0 software was used for the semi-variance function model fitting. ArcGIS10.2 was used for the Kriging interpolation to draw the distribution map of the sampling points and the distribution map of the soil heavy metal content.

\section{Evaluation method of the soil heavy metal pollution}

\subsection{The single factor index method}

The single factor index method was used to grade the cumulative pollution degree of a single heavy metal in the soil[12-16], and its expression is as follows:

$$
P_{i}=C_{i} / S_{i}(i=1,2,3, \ldots, n),
$$

where $P_{i}$ is the single factor pollution index of a heavy metal, $i$, and its classification is 
shown in Table $1 ; \mathrm{C}_{\mathrm{i}}$ is the actual test value of a heavy metal, $\mathrm{i}\left(\mathrm{mg} \bullet \mathrm{kg}^{-1}\right) ; \mathrm{S}_{\mathrm{i}}$ is the evaluation standard value of a heavy metal, $\mathrm{i}$; and $\mathrm{n}$ is the total number of heavy metals participating in the evaluation.

\subsection{The Nemero index method}

The Nemero index not only highlights the impact of a high concentration of pollutants on environmental quality but also considers the average value of a single factor pollution index that can fully reflect the average pollution level of various pollutants in the soil. It is a comprehensive evaluation method of environmental quality that is widely used. Its expression is as follows:

$$
P_{N}=\sqrt{\frac{\left(P_{i}\right)^{2} \text { average }+\left(P_{i}\right)^{2} \max }{2}},
$$

where $P_{\mathrm{N}}$ is the Nemerow comprehensive pollution index, and its classification is shown in Table 1; $\mathrm{P}_{\mathrm{i}}$ average is the average single factor index of each heavy metal; and $\mathrm{Pi}_{\mathrm{i} \text { max }}$ is the maximum single factor index of a heavy metal, i.

\subsection{The geological accumulation index method}

The geological accumulation index[17-19], also known as the Muller index, was first proposed by Muller, a scientist at the University of Heidelberg in Germany in the late 1960s. It is primarily used to study the degree of heavy metal pollution in sediments and other substances. It not only considers the background value of natural processes but also pays attention to the influence of human activities on heavy metal pollution. Its expression is as follows:

$$
I_{\text {geo }}=\log _{2}\left(C_{i} / K \cdot B_{i}\right),
$$

where Igeo is the geological accumulation index, and its classification is shown in Table 1; $C_{i}$ is the measured value of a heavy metal, $i$, in a soil; $B_{i}$ is the background value of a heavy metal, $\mathrm{i}$, in a soil in the rock strata; and $\mathrm{K}$ is the coefficient (generally $\mathrm{K}$ is 1.5).

\begin{tabular}{|c|c|c|c|c|c|c|}
\hline \multicolumn{2}{|c|}{ Single factor index } & \multicolumn{2}{|c|}{ Nemero index } & \multicolumn{3}{|c|}{ Geological accumulation index } \\
\hline$P_{i}$ & $\begin{array}{l}\text { Pollution } \\
\text { degree }\end{array}$ & $P_{N}$ & Pollution degree & $I_{g e o}$ & series & Pollution degree \\
\hline$P_{i} \leq 1$ & No pollution & $P_{N} \leq 0.7$ & Clean & $I_{g e o} \leq 0$ & 0 & No pollution \\
\hline $1<P_{i} \leq 2$ & Slight pollution & $0.7<P_{N}<1$ & Cordon & $0<I_{g e o} \leq 1$ & 1 & No pollution moderate \\
\hline $2<P_{i} \leq 3$ & Light pollution & $1<P_{N} \leq 2$ & Light pollution & $1<I_{g e o} \leq 2$ & 2 & Moderately polluted \\
\hline $3<P_{i} \leq 5$ & $\begin{array}{c}\text { Moderately } \\
\text { polluted }\end{array}$ & $2<P_{N} \leq 3$ & $\begin{array}{c}\text { Moderately } \\
\text { polluted }\end{array}$ & $2<I_{g e o} \leq 3$ & 3 & $\begin{array}{c}\text { Moderately Pollution } \\
\text { Severe }\end{array}$ \\
\hline$P_{i}>5$ & Heavy pollution & $P_{N}>3$ & Heavy pollution & $3<I_{\text {geo }} \leq 4$ & 4 & Heavy pollution \\
\hline- & - & - & - & $4<I_{g e o} \leq 5$ & 5 & higher heavy pollution \\
\hline
\end{tabular}

Table 1 Standards for classification of soil heavy metal pollution levels 


\begin{tabular}{llllllll}
\hline- & - & - & $I_{\text {geo }}>5$ & 6 & Very heavy pollution \\
\hline
\end{tabular}

\subsection{Methods for assessing the potential ecological risks}

The potential ecological risk index method was proposed by Hakanson[20-25], a Swedish scholar, to evaluate heavy metal pollution and its ecological harm. The method combines the ecological effect, environmental effect, and toxicology of heavy metals. It can comprehensively reflect the impact of heavy metals on the ecological environment. Its expression is as follows:

$$
E_{i}=T_{r}^{i} \times\left(C_{i} / C_{0 i}\right),
$$

where $\mathrm{C}_{\mathrm{i}}$ is the measured values; $\mathrm{C}_{0 \mathrm{i}}$ is parameter ratios of a heavy metal, $\mathrm{i} ; \mathrm{T}_{\mathrm{r}} \mathrm{is}$ the toxicity coefficient of a heavy metal, $\mathrm{i}$; and the toxicity response coefficients of heavy metals $\mathrm{As}, \mathrm{Cu}$, and $\mathrm{Pb}$ are ten, five, and five, respectively.

The comprehensive potential ecological risk index is as follows:

$$
R I=\sum E_{i},
$$

where RI is the comprehensive potential ecological risk index of various heavy metals in the study area; and $\mathrm{E}_{\mathrm{i}}$ is the potential ecological harm index of a heavy metal, $\mathrm{i}$. Its classification is shown in Table2

\begin{tabular}{|c|c|c|c|c|}
\hline Rank & $\begin{array}{c}\text { potential ecological risk } \\
\text { index }\end{array}$ & Degree of risk & $\begin{array}{c}\text { comprehensive potential } \\
\text { ecological risk }\end{array}$ & Degree of risk \\
\hline 1 & $E_{i} \leq 40$ & Low potential risk & $R I \leq 150$ & $\begin{array}{c}\text { Minor ecological } \\
\text { hazard }\end{array}$ \\
\hline 2 & $40<E_{i} \leq 80$ & $\begin{array}{c}\text { Medium potential } \\
\text { risk }\end{array}$ & $150<R I \leq 300$ & $\begin{array}{c}\text { Moderate ecological } \\
\text { hazard }\end{array}$ \\
\hline 3 & $80<E_{i} \leq 160$ & $\begin{array}{l}\text { Medium high } \\
\text { potential risk }\end{array}$ & $300<R I \leq 600$ & $\begin{array}{l}\text { Strong ecological } \\
\text { hazard }\end{array}$ \\
\hline 4 & $160<\mathrm{E}_{i} \leq 320$ & High potential risk & $R I>600$ & $\begin{array}{c}\text { Very strong ecological } \\
\text { hazard }\end{array}$ \\
\hline 5 & $E_{i} \geq 320$ & $\begin{array}{c}\text { Very high potential } \\
\text { risk }\end{array}$ & - & - \\
\hline
\end{tabular}

Table 2. Potential ecological risk coefficient and potential ecological risk index classification

\section{Results and analysis}

\subsection{Statistical analysis of the heavy metals in the soil}

According to the test results, the $\mathrm{pH}$ values of the soil samples were all greater than 7.5. As can be seen from Table 3, the average contents of $\mathrm{Cu}, \mathrm{As}$, and $\mathrm{Pb}$ in the soil in the study area were 13.16, 8.28, and 15.971 MGKG, respectively, which were within the range of the secondlevel national standard and the background value[39,40]. However, a few sample points exceeded the background value of the soil. The proportions of the over-point samples for $\mathrm{Cu}$, 
$\mathrm{As}$, and $\mathrm{Pb}$ were $8.33 \%, 16.67 \%$, and $13.33 \%$, respectively. The phenomenon of the over-point values exceeded the background values, and this indicated that the three heavy metal elements in the study area had accumulated to different degrees. Compared with the Yichang Irrigation Area and the Ulate Irrigation Area[26,27], the average As content in the Jiefangzha Irrigation Area was higher, but within the range of the background value. The contents of $\mathrm{Pb}$ were similar in the two areas. The content of the As element in the Wuliangsuhai water body was much higher than that in the Inner Mongolia section of the Yellow River[28-29]; however, it was similar to the Jiefangzha Irrigation Area, as shown in Table 4. This indicated that the drainage of the Jiefangzha Irrigation Area had a certain contribution to this value. The degree of spatial variability can be roughly classified according to the variation coefficient $(\mathrm{CV}<10 \%$ is weak variability, $10 \% \leq \mathrm{CV} \leq 100 \%$ is moderate variability, and $\mathrm{CV}>100 \%$ is strong variability). As shown in Table 3, the variation coefficients of $\mathrm{Cu}$, As, and $\mathrm{Pb}$ were $25.46 \%, 37.56 \%$, and $16.16 \%$, respectively, belonging to moderate variability. The three heavy metal elements were affected by exogenous factors, such as irrigation water, atmospheric deposition, pesticide and fertilizer use, and traffic pollution.

Table 3. Descriptive statistical analyses of the soil heavy metal contents $\left(\mathrm{mg} \cdot \mathrm{kg}^{-1}\right)$

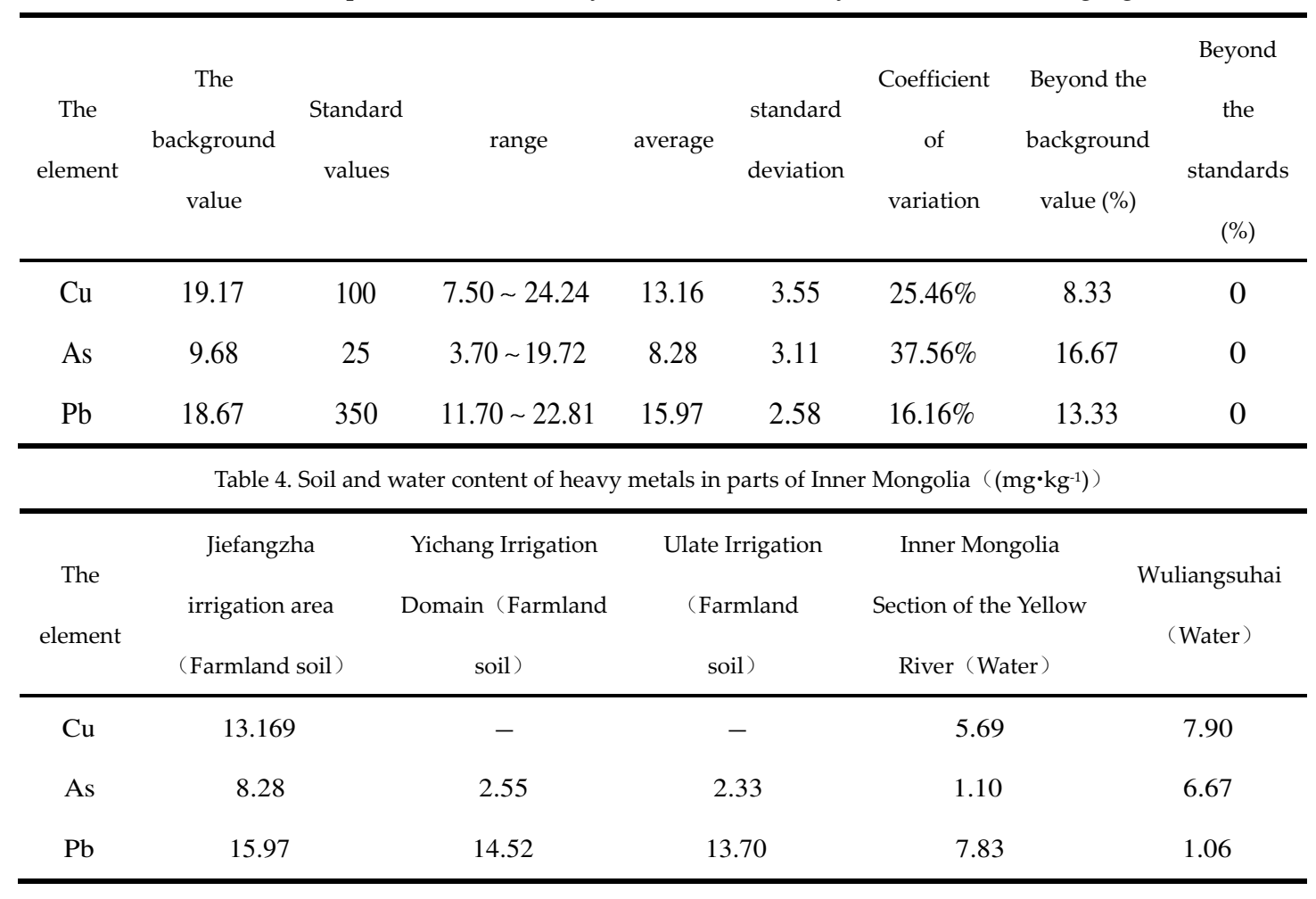

\subsection{Evaluation of the soil heavy metal pollution}

Using the environmental background value of the Hetao Irrigation Area As value as the evaluation standard, Table 5 shows that the average value of a single factor pollution index for the three heavy metal elements in the study area was $\mathrm{As}=\mathrm{Pb}>\mathrm{Cu}$, between 0.69 and 0.86 . This indicated different degrees of pollution. In the samples, $15 \%$ and $1.67 \%$ of the As elements were slightly polluted or lightly polluted, and approximately $10 \%$ of the $\mathrm{Pb}$ and $\mathrm{Cu}$ elements were slightly polluted. This indicated that the accumulation and enrichment of As in the soil was more serious than that of the $\mathrm{Pb}$ and $\mathrm{Cu}$ elements. Table 6 shows the evaluation results of the Nemero comprehensive pollution index for heavy metals in the farmland soils in the study 
area. When the soil environmental background value of the Hetao Irrigated Area was used as the evaluation standard, the proportion of samples with light pollution and a warning line was $15 \%$ and $66.67 \%$, respectively. This indicated that there was a certain degree of heavy metal accumulation in the farmland soil in the study area. The study area was at a clean level when the second-level national soil environmental quality standard was used as the evaluation standard. According to the geological accumulation index results, $3.33 \%$ of the soil samples had moderate or no pollution, and both $\mathrm{Pb}$ and $\mathrm{Cu}$ were in the no pollution range, which was consistent with the evaluation results of the single factor pollution index, as shown in Table 7.

Table 5. Evaluation results of the soil heavy metal single factor pollution index

\begin{tabular}{|c|c|c|c|c|c|c|c|}
\hline \multirow{2}{*}{$\begin{array}{l}\text { The } \\
\text { element }\end{array}$} & \multicolumn{3}{|c|}{ Single factor index method } & \multicolumn{3}{|c|}{ The degree of risk } & \multirow[b]{2}{*}{$\begin{array}{l}\text { Heavy } \\
\text { pollution }\end{array}$} \\
\hline & range & average & No pollution & $\begin{array}{l}\text { Slight } \\
\text { pollution }\end{array}$ & $\begin{array}{l}\text { Light } \\
\text { pollution }\end{array}$ & $\begin{array}{c}\text { Moderately } \\
\text { polluted }\end{array}$ & \\
\hline $\mathrm{Cu}$ & $0.39 \sim 1.26$ & 0.69 & $91.67 \%$ & $8.33 \%$ & 0 & 0 & 0 \\
\hline As & $0.38 \sim 2.04$ & 0.86 & $83.33 \%$ & $15.00 \%$ & $1.67 \%$ & 0 & 0 \\
\hline $\mathrm{Pb}$ & $0.63 \sim 1.22$ & 0.86 & $86.67 \%$ & $13.33 \%$ & 0 & 0 & 0 \\
\hline
\end{tabular}

Table 6. Overall evaluation results of soil heavy metals in the study area

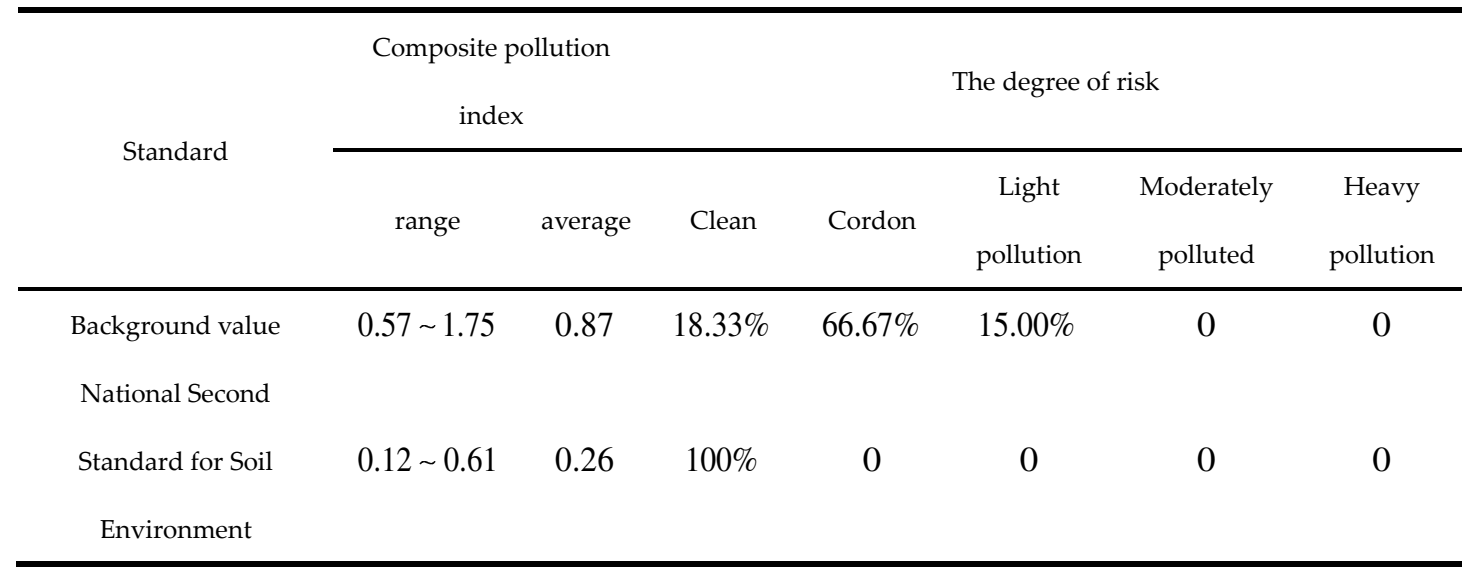

Table 7. Results of the geological accumulation index of soil heavy metals in the study area

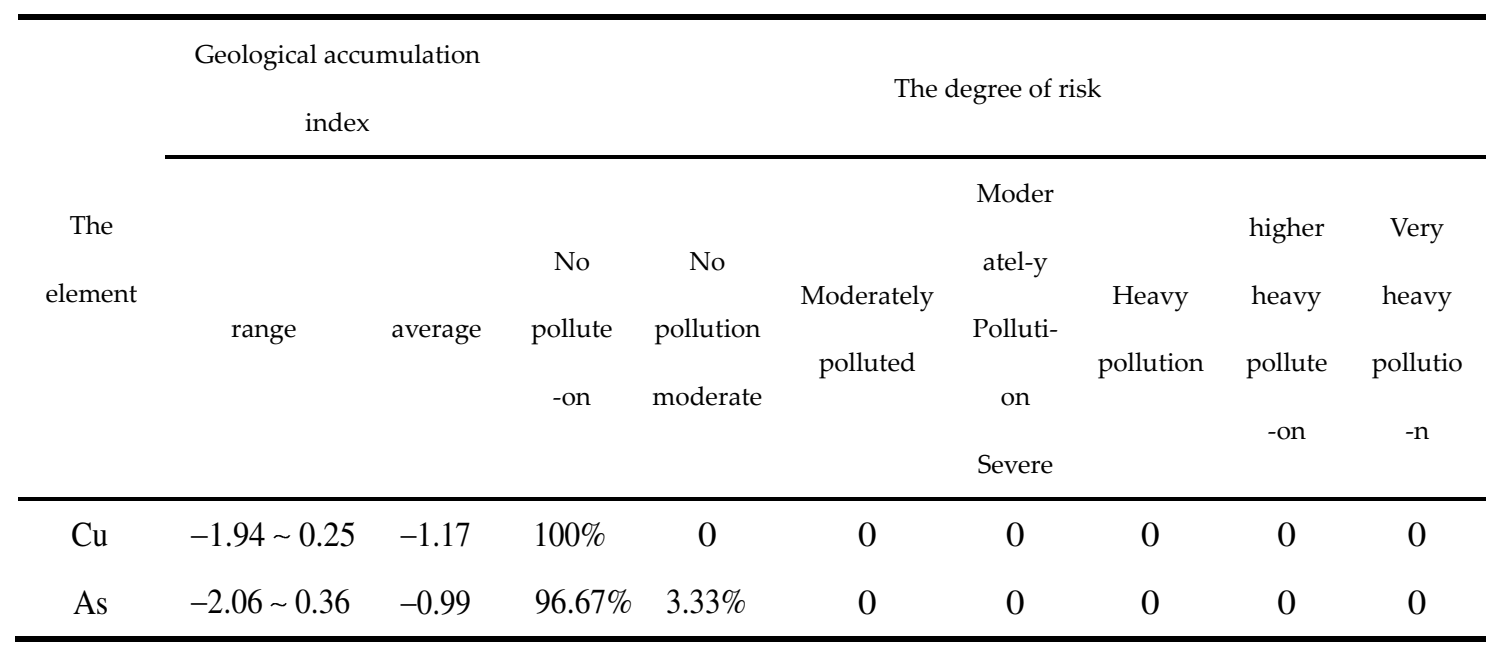




\begin{tabular}{llllllllll}
\hline $\mathrm{Pb}$ & $-1.26 \sim 0.30$ & -0.83 & $100 \%$ & 0 & 0 & 0 & 0 & 0 & 0 \\
\hline
\end{tabular}

\subsection{The potential ecological risk assessment of heavy metals in the soil}

The potential ecological harm coefficient and the comprehensive potential ecological harm coefficient of the single heavy metals were evaluated using the soil environmental background value of the Hetao Irrigation Area. Table 8 shows the average potential ecological harm coefficient of each heavy metal As (8.56) $>\mathrm{Pb}(4.28)>\mathrm{Cu}$ (3.43) was less than 40 , which is a low potential risk. The comprehensive potential ecological harm coefficient was 16.27. This indicated that the heavy metals in the soil of the irrigated area showed a slight harm degree, which was consistent with the ecological risk level of the soil from the irrigated area in the Urat region studied by Tian Zhiqiang[22].

Table 8. Ecological Risk Assessment of Soil Heavy Metal Pollution

\begin{tabular}{cccc}
\hline Item & $\mathrm{Cu}$ & As & $\mathrm{Pb}$ \\
\hline$E_{i}$ & $1.96 \sim 6.32$ & $3.82 \sim 20.38$ & $3.13 \sim 6.11$ \\
$\bar{E}_{i}$ & 3.43 & 8.56 & 4.28 \\
Risk level & Low potential risk & Low potential risk & \\
$\overline{R I}$ & & 16.27 & \\
Risk level & & Minor ecological hazard & \\
\hline
\end{tabular}

\section{Soil source analysis and spatial distribution of the heavy metal content}

A correlation analysis and principal component analysis can well identify the sources of soil heavy metal pollution[30,31]. Heavy metal elements are primarily affected by human activities and parent rocks. Table 9 shows the correlation analysis values of the three heavy metals. It can be concluded that the three heavy metal elements had greater homology and the hidden danger of compound pollution. The principal component analysis using SPSS showed that the variance contribution rate of PC1 was $86.64 \%$, which attained the analysis standard. The $\mathrm{As}, \mathrm{Pb}$, and $\mathrm{Cu}$ had a large load on PC1, with obvious high values at $0.937,0.820$, and 0.842 , respectively. The possible factors that led to the accumulation of heavy metals in this area were pesticides, chemical fertilizers, excessive use of mulching films, and irrigation that used polluted water.

Table 9. Correlation coefficients of soil heavy metal elements in the study area

\begin{tabular}{cccc}
\hline The elemen & $\mathrm{Cu}$ & $\mathrm{As}$ & $\mathrm{Pb}$ \\
\hline $\mathrm{Cu}$ & 1 & & \\
$\mathrm{As}$ & $0.835^{* *}$ & 1 & \\
$\mathrm{~Pb}$ & $0.863^{* *}$ & $0.697^{* *}$ & 1 \\
\hline
\end{tabular}

Note: ${ }^{* *}$. At the 0.01 level (two-tailed), the correlation is significant

The K-S method in the SPSS software was used to test the normal distribution of the data. 
The results showed that the $\mathrm{Pb}$ element obeyed a normal distribution, and $\mathrm{Cu}$ and As obeyed a normal distribution after logarithmic conversion. GS+9.0 geostatistics software was used to analyze the data by semi-variograms. According to the fitting results of the variograms theory model, $\mathrm{Pb}$ was a spherical model, and $\mathrm{Cu}$ and As were Gaussian models. In addition, the nugget coefficients of the three types of heavy metals were all 0.502-0.522, indicating a medium spatial correlation. The Geostatistical Analyst function in ArcGIS10.2 was used to interpolate the heavy metal content. The Nemero composite index and potential ecological harm composite index for the study area were found using the ordinary Kriging method[32-38], as shown in Figures 2 and 3.

The contents of the $\mathrm{Cu}, \mathrm{As}$, and $\mathrm{Pb}$ in the study area generally displayed a trend of high in northwest China and low in southeast China, with an increasing gradient change from the southeast to the northwest. The spatial distribution of the pollution of the three heavy metals was similar, showing a gradient distribution. The pollution of the three heavy metals was more serious in northwest China, and the pollution range was wider and more serious than that of $\mathrm{Pb}$ and $\mathrm{Cu}$. Some points beyond the background value were distributed in the northwest area of the liberating gate irrigation area. The primary reason for the above phenomenon was the accumulation of heavy metals caused by the long-term residual accumulation of toxic and harmful substances in irrigation water, pesticides, fertilizers, and mulching film utilized in northwest China where crops are planted.

According to the comprehensive evaluation shown in Figure 3, the accumulation degree of heavy metals in the northwest of the study area was more serious than that in the other polluted areas. According to the evaluation result chart of the potential ecological harm index method, the study area was in slight ecological harm as a whole. However, the ecological element in northwest China was more serious. This was consistent with the Nemero comprehensive pollution index evaluation results.
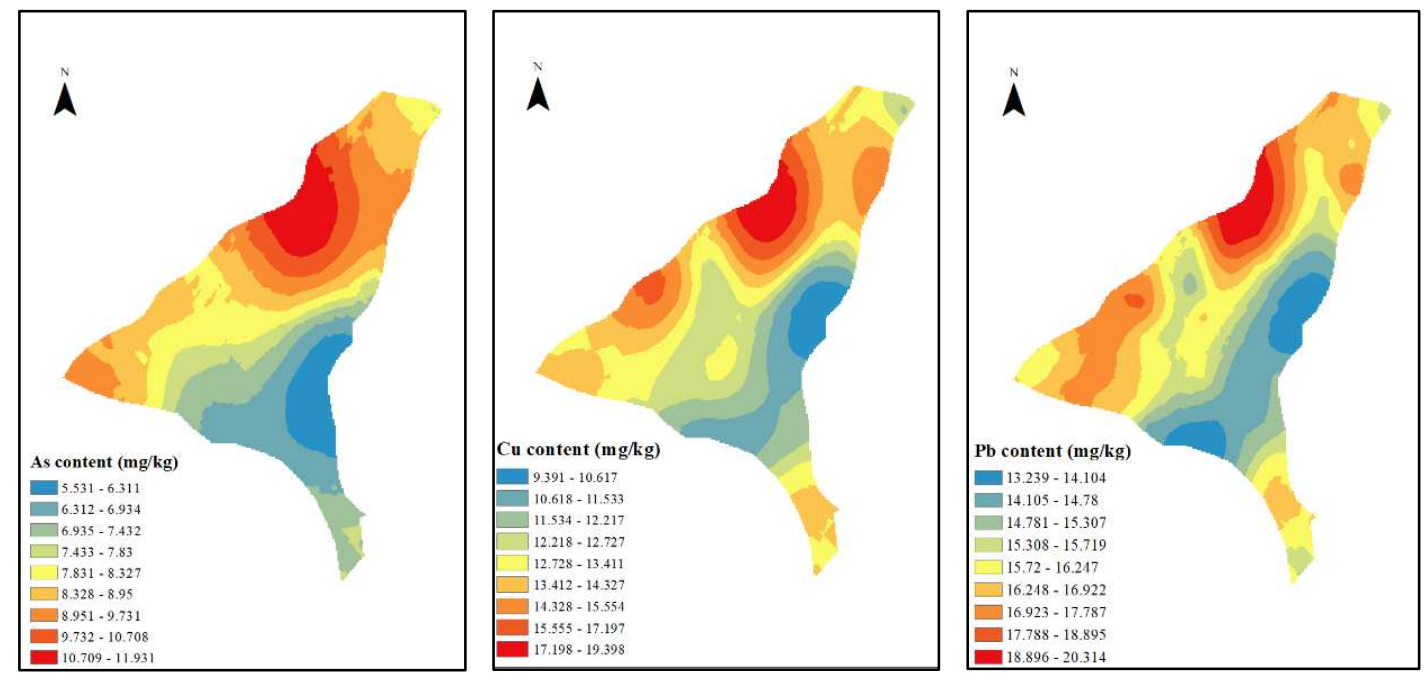

Figure 2. Spatial distribution map of the heavy metal element contents in the soil 

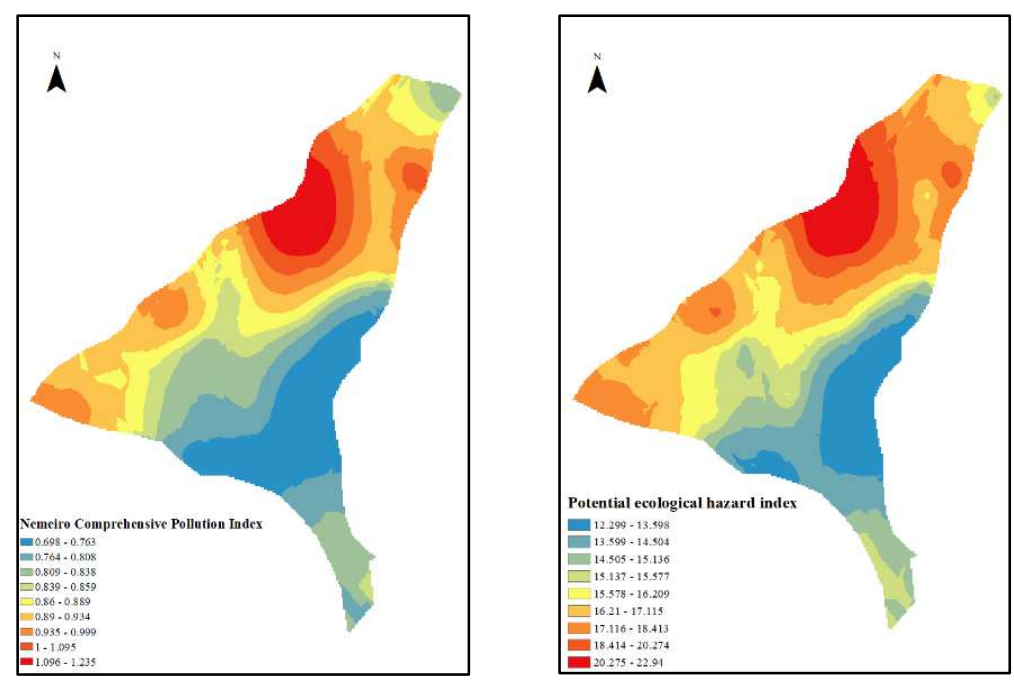

Figure 3. Comprehensive evaluation results of the soil heavy metal elements

\section{Conclusions}

The contents of $\mathrm{Cu}, \mathrm{As}$, and $\mathrm{Pb}$ in farmland soil samples from the Jiefangzha Irrigation Area exceeded the background value by $8.33 \%, 16.67 \%$, and $13.33 \%$, respectively. The variation degree was moderate, and the three heavy metal elements were affected by exogenous factors, such as atmospheric deposition, pesticide, fertilizer use, and traffic pollution. The single factor index method and the geological accumulation index showed that the pollution degree of As was high. The average Nemero composite pollution index was 0.87 , indicating the warning level.

In the Hetao Irrigation Area regarding the soil environmental background value of the As evaluation standard, the potential ecological harm coefficient of the three types of heavy metals in the study area had means rated as $\mathrm{As}>\mathrm{Pb}>\mathrm{Cu}$. This was an overall low potential risk, and the potential ecological comprehensive index was 16.27. This demonstrated that the overall performance of the heavy metals had the potential for slight damage. Hence, the control of heavy metal pollution and soil heavy metal pollution monitoring should be considered for this area.

The correlation analysis showed that there was a significant correlation between $\mathrm{As}-\mathrm{Pb}-\mathrm{Cu}$, and it was inferred that the sources of the three heavy metals were similar. The principal component analysis results showed that the variance contribution rate of the first principal component was $86.64 \%$, which further indicated that $\mathrm{As}, \mathrm{Pb}$, and $\mathrm{Cu}$ were probably from the same source. In addition, their accumulation in the soil was caused by human factors.

The results of the semi-variance function model fitting showed that $\mathrm{Pb}$ was a spherical model, and $\mathrm{Cu}$ and As were Gaussian models. The contents of $\mathrm{As}, \mathrm{Pb}$, and $\mathrm{Cu}$ in the study area were generally higher in the northwest region and lower in the southeast region. The northwest region is primarily used for crops, and the long-term residual accumulation of toxic and harmful substances in irrigation water, pesticides, fertilizers, and mulching film may have caused the accumulation of heavy metals.

Acknowledgements: This research was funded by the National Natural Science Foundation of China (51469023) ;Inner Mongolia Agricultural University High-level Talents Introduction Scientific Research Startup Project（NDYB2016-22）; Science and Technology Innovation Fund 
Project for Undergraduates of Inner Mongolia Agricultural University(KJCX2020018); the Inner Mongolia Autonomous Region Science and Technology Department (2021MS04012); National Key Research and Development Program of China (2019YFC0609204).

Author Contributions: Q.Z , J.L and G.P conceived of, designed the experiments and gave critical commentary revisions; L.Y and Q.M performed the experiments, analyzed the data and wrote the paper; Z.S and F.S .data curation and reviewed the paper .Y.L contributed analysis tools; Y.Z. also performed the experiments and collected the data. All authors have read and agreed to the published version of the manuscript.

Declarations: Conflict of interest The authors do not have conflicts of interest or competing interest to declare.

\section{References}

1. Dai, B.; Lv, J.S.; Zhang, J.C.; Zhang, Z.L.; Liu, Y.; Zhou, R.J. Assessment of Sources, Spatial Distribution and Ecological Risk of Heavy Metals in Soils in a Typical Industry-based City of Shandong Province, Eastern China [J]. Environmental Science,2015.36(02):507-515

2. Li, H.W.; Shang, E.P.; Zhang, H.Q.; Xu, E.Q. Comparative research on spatio-temporal variability of heavy metal pollution in cultivated soils-A case study of Huang-Huai-Hai Plain and middle reaches of the Yangtze River and Jianghuai Region[J]. China Environmental Science ,2018,38(09):3464-3473.

3. Gao, Z.G. Evaluation of heavy metal pollution and its ecological risk in one river reach of a gold mine in Inner Mongolia, Northern China[J]. International Biodeterioration \& Biodegradation,2018,128.

4. Zhou, Y.; Chen, Q.; Deng, S.P.; Wan, J.Z.; Zhang, S.T.; Long, T.; Li, Q.; Lin, Y.S.; Wu, Y.J. Principal Component Analysis and Ecological Risk Assessment of Heavy Metals in Farmland Soils around a $\mathrm{Pb}-\mathrm{Zn}$ Mine in Southwestern China[J], Environmental Science, 2018,39(06):2884-2892.

5. Gao, X.Y.; Tang, Z.Y.; Li, J.H. Current Situation of Soil Environmental Pollution and Countermeasures of Prevention and Control in China[J], Jiangsu Environmental Science and Technology, 2006(02):52-55.

6. Ao, M.; Chai, G.Q.; Fan, C.W.; Liu, G.H.; Qin, S.; Wang, P. Evaluation of potential pollution risk and source analysis of heavy metals in paddy soil and rice[J], Transactions of the Chinese Society of Agricultural Engineering, 2019,35(06):198-205+324.

7. Huang, D.J.; Zhang, Y.M. Biological monitoring and ecological remediation in Lanzhou section of the Yellow River[J],Science \& Technology Review, 2020,38(17):60-65.

8. Xia, X.J.; Zheng, J.; Wan, Q. Analysis of the Heavy Metal Pollution of Sediment in Middle and Lower Yellow River, YELLOW RIVER, 2018,40(08):19-21+26.

9. Zhai, Z.M.; Shi, W.J.; Guo, J.Z.; Liu, L. Study on Comprehensive Control Measures of Soil Salinity in Jiefangzha[J], Journal of Soil and Water Conservation, 2021,35(01):314-318+325.

10. Yao, Y.T.; Pei, G.X.; Zhang, Q.; Wang, J.; Shi, F. Residual and Distribution Characteristics of PCBs in Surface Soil of Jiefangzha Irrigation Field[J], Soils, ,2020,52(01):167-173.

11. Zheng, Q.; Shi, H.B.; Li, X.Y.; Liu, M.H.; Sun, W.; Wang, G.S.; Zhang, Y. Study on the Quantitative Relationship Between Vegetation Index and Groundwater Depth in Jiefangzha Irrigation Area in the Hetao Irrigation District[J], Iournal of Soil and Water Conservation, 2021,35(01):301-306+313.

12. Wu, Y.; Yang, J.; Zhou, X.Y.; Lei, M.; Gao, D.; Qiao, P.W.; Du, G.D. Risk Assessment of Heavy Metal Contamination in Farmland Soil in Du"an Autonomous County of Guangxi Zhuang Autonomous Region,China.ENVIRONMENTAL SCIENCE,2015,36(08):2964-2971. 
13. Liu, S.; Wu, Q.Y.; Cao, X.J.; Wang, J.N.; Zhang, L.L.; Cai, D.Q.; Zhou, L.Y.; Liu, N. Pollution Assessment and Spatial Distribution Characteristics of Heavy Metals in Soils of Coal Mining Area in Longkou City[J].ENVIRONMENTAL SCIENCE,2016,37(01):270-279.

14. Yan, F.; Liu, C.L.; Wei, B.W. Evaluation of heavy metal pollution in the sediment of Poyang Lake based on stochastic geo-accumulation model (SGM)[J]. Science of the Total Environment,2019,659.

15. Liu, Y.T.; Fang, Z.D.; Xie, C.X.; Li, J. Analysis of Existing Speciation and Evaluation of Heavy Metals Pollution of Soil in a Shooting Range[J]. Nature Environment \& Polution Technology,2014,13(3): 449456.

16. Wang, J.X.; Li, X.L.; He, Q.M.; Chen, Y.C.; Cai, Q.; Luo, L.; Zhao, X. Characterization and risk assessment of heavy metal pollution in agricultural soils in Three Gorge Reservoir Area.[J].Transactions of the Chinese Society of Agricultural Engineering,2018,34(08):227-234.

17. Xu, Y.H.; Sun, Q.Q.; Yi, L.; Yin, X.J.; Wang, A.J.; Li, Y.H.; Chen,J. The source of natural and anthropogenic heavy metals in the sediments of the Minjiang River Estuary (SE China): implications for historical pollution.[J]. The Science of the total environment,2014,493: 729-736.

18. Mirella Peña-Icart,Edenir Rodrigues Pereira-Filho,Lucimar Lopes Fialho,Joaquim A. Nóbrega,Carlos Alonso-Hernández, Yoelvis Bolaños-Alvarez,Mario S. Pomares-Alfonso. Combining contamination indexes, sediment quality guidelines and multivariate data analysis for metal pollution assessment in marine sediments of Cienfuegos Bay, Cuba[J]. Chemosphere,2017,168.

19. Yang, G.; Shen, F.; Zhong, G.J.; Xie, L.P.; Wang, Y.J.; Wu,J. Concentration and health risk of heavy metals in crops and soils in a zinc-lead mining area in southwest mountainous regions[J],Acta Scientiae Circumstantiae,2011,31(09):2014-2021.

20. Zhou, Y.; Chen, Q.; Deng, S.P.; Wan, J.Z.; Zhang, S.T.; Long, T.; Li, Q.; Lin, Y.S.; Wu, Y.J. Principal Component Analysis and Ecological Risk Assessment of Heavy Metals in Farmland Soils around a $\mathrm{Pb}-\mathrm{Zn}$ Mine in Southwestern China.[J]. Huan jing ke xue= Huanjing kexue,2018,39(6): 2884-2892.

21. Liu, C.; Cui, J.; Jiang, G.F.; Chen, X.F.; Wang, L.; Fang, C.M. Soil Heavy Metal Pollution Assessment Near the Largest Landfill of China[J]. Soil and Sediment Contamination: An International Journal,2013,22(4): 390-403

22. Zhang, Z.Y.; Yang, X.D.; Yang, S.T. Heavy metal pollution assessment, source identification, and health risk evaluation in Aibi Lake of northwest China[J]. Springer International Publishing,2018,190(2): ):69.

23. Pang, Y.; Tong, Y.A.; Liang, L.Y.; Ji, P.H.; Tang, X.W. Assessment of Heavy Metal Pollution in SoilCrop System on Sewage Irrigated Farmland, Journal of Agricultural Machinery, 2015,46(01):148-154.

24. Long, Z.J.; Huang, Y.; Zhang, W.; Shi, Z.L.; Yu, D.; Chen, Y.; Liu, C.; Wang, R. Effect of different industrial activities on soil heavy metal pollution, ecological risk, and health risk[J]. Environmental Monitoring and Assessment,2021,193(1): 6-12.

25. Han, C.L.; Tian, Z.Q.; Huo, Y.Z. Investigation and Evaluation of Farmland Soil Heavy Metal Pollution in a Typical Area of Hetao Irrigation District.2020(01):74-75+78.

26. Tian, Z.Q.; Han, C.Y.; Huo, Y.Z. The characteristics and ecological risk of farmland soil heavy metal pollution in North Urad Irrigation Area,JOURNAL OF NORTHERN AGRICUL.TURE,2019, ,47(06):79.

27. Wang, L.M.; Zhang, S.; Zhao, S.N. Spatial distribution characteristics of heavy metals in Ulansuhai Lake[J]. Journal of Environment and Health,2014,31(12):1088-1089+1129.

28. Zhao, S.Z.; Liu, L.P.; Wang, X.K. Characteristics and Ecological Risk of Heavy Metals in overlying 
Water, Suspended Particles and Bed Mud in the Inner Mongolia Stretch of the Yellow River [J]Geoscience,2008(02):304-312.

29. Zhang, L.K.; Li, H.P.; Huang, X.M.; Li, Y.M.; Jiao, K.L.; Sun, P.; Wang, W.D. Soil Heavy Metal Spatial Distribution and Source Analysis Around an Aluminum Plant in Baotou.ENVIRONMENTAL SCIENCE,2016,37(03):1139-1146.

30. Zhao, L.; Xu, Y.F.; Hou, H.; Shangguan, Y.X.; Li, F.S. Source identification and health risk assessment of metals in urban soils around the Tanggu chemical industrial district, Tianjin, China[J]. Science of the Total Environment,2014,468-469.

31. Song, J.X.; Zhu, Q.; Jiang, X.S.; Zhao, H.Y.; Liang, Y.H.; Luo, Y.X.; Wang, Q.; Zhao, L.L. GIS-Based Heavy Metals Risk Assessment of Agricultural Soils-A Case Study of Baguazhou,Nanjing.ACTA PEDOLOGICA SINICA,2017,54(01):81-91.

32. Jiang, F.F.; Sun, D.F.; Li, H.; Zhou, L.D. Risk grade assessment for farmland pollution of heavy metals in Beijing, Transactions of the CSAF,2011,27(08):330-337.

33. Li, X.D.; Lee, S.L.; Wong, S.C.; Shi, W.Z.; Thornton Iain. The study of metal contamination in urban soils of Hong Kong using a GIS-based approach.[J]. Environmental pollution (Barking, Essex : 1987),2004,129(1): 113-124.

34. Xu, G.; Pei, S.F.; Liu, J.; Gao, M.S.; Hu, G.; Kong, X.H.; Surface sediment properties and heavy metal pollution assessment in the near-shore area, north Shandong Peninsula[J]. Marine Pollution Bulletin,2015,95(1)::395-401.

35. Xu, X.H.; Zhang, X.D.; Peng, Y.X.; Li, R.Y.; Luo, X.S.; Zhao, Y.C. Spatial Distribution and Source Apportionment of Agricultural Soil Heavy Metals in a Rapidly Developing Area in East China[J]. Bulletin of Environmental Contamination and Toxicology,2021(prepublish): 33-39.

36. Wang, R.; Deng, H.; Yan, S.M.; He, Z.X.; Zhou, J.; Liang, S.B.; Zeng, Q.Q. Assessment and Source Analysis of Heavy Metal Pollution in Farmland Soils in Southern Youyang County,Chongqing[J].Environmental Science,2020,41(10):4749-4756.

37. Wang, Y.Q.; Bai, Y.R.; Wang, J.Y. Distribution of Soil Heavy Metal and Pollution Evaluation on the Different Sampling Scales in Farmland on Yellow River Irrigation Area of Ningxia:A Case Study in Xingqing County of Yinchuan City, Environmental Science 2014,35(07):2714-2720.

38. Soil environmental quality standards [S],GB 15618-1995.

39. Gao, H.X.; Wang, K.X.; Zhang, Q.; Li, S.B. Characteristics of Soil Value in Hetao Region, Inner Mongolia, Geology and resources, 2007(03):209-212. 